\title{
Atributos estruturais e produtivos de capim-marandu em resposta à suplementação alimentar de bovinos e a ciclos de pastejo
}

\author{
Carlos Augusto de Miranda Gomide( ${ }^{(1)}$, Ricardo Andrade Reis ${ }^{(2)}$, Flávia Fernanda Simili(3) \\ e Andréia Luciane Moreira ${ }^{(3)}$
}

\begin{abstract}
(1)Embrapa Gado de Leite, Rua Eugênio do Nascimento, no 610, CEP 36038-330 Juiz de Fora, MG. E-mail: cagomide@cnpgl.embrapa.br (2)Universidade Estadual Paulista, Faculdade de Ciências Agrárias e Veterinárias, Avenida Paulo Donato Castellane, s/no, CEP 14884-900 Jaboticabal, SP. E-mail: rareis@fcav.unesp.br ${ }^{(3)}$ Agência Paulista de Tecnologia dos Agronegócios, Avenida Miguel Stéfano, no 3.900, CEP 04301-903 São Paulo, SP. E-mail: flaviasimili@gmail.com, aluciane@aptaregional.sp.gov.br
\end{abstract}

Resumo - O objetivo deste trabalho foi avaliar as alterações estruturais e produtivas de capim-marandu (Brachiaria brizantha cv. Marandu) em resposta à suplementação alimentar de bovinos e a ciclos de pastejo. Os níveis de suplementação com concentrado à base de polpa cítrica, milho, farelo de soja e ureia foram 0,2, 0,6 e $1 \%$ do peso vivo. O delineamento experimental foi o de blocos ao acaso, com arranjo em parcelas subdivididas no tempo, com os níveis de suplementação nas parcelas e os ciclos de pastejo nas subparcelas. Os efeitos da suplementação alimentar dos animais sobre o pasto foram detectados sobre o índice de área foliar, interceptação luminosa e relação folha/colmo, em pré-pastejo. Os menores valores foram observados na suplementação de $0,2 \%$ do peso vivo. No pós-pastejo, a massa de folhas e a relação folha/colmo foram menores com a menor suplementação $(0,2 \%)$. Os ciclos de pastejo afetaram as características produtivas e estruturais do pasto, bem como os índices morfogênicos do capim-marandu. Apenas a massa de material morto aumentou, enquanto o número e o peso de perfilhos não foi afetado pelos ciclos de pastejo. O pasto de capim-marandu foi influenciado pela suplementação alimentar dos bovinos. Com o suceder dos ciclos de pastejo, do verão para o outono, há redução do crescimento do pasto, com prejuízos à sua estrutura.

Termos para indexação: Brachiaria brizantha, índice de área foliar, massa de forragem, morfogênese, relação folha/colmo.

\section{Productive and structural traits of marandu grass pasture in response to supplemental bovine feeding levels and grazing cycles}

\begin{abstract}
The objective of this work was to evaluate the productive and structural traits of marandu grass (Brachiaria brizantha $\mathrm{cv}$. Marandu) pasture in response to supplemental bovine feeding levels and to grazing cycles. The evaluated levels of concentrate feeding based on citric pulp, corn, soybean meal and urea were: $0.2,0.6$, and $1 \%$ body live weight. A completely randomized block design was used, with split plots in time, in which supplementation levels were the plots and grazing periods were the subplots. Supplemental feeding levels affected the grass canopy traits. Changes were detected in leaf area index, light interception, and leaf/stem ratio under pre-grazed pasture conditions. The lowest figures were observed for the supplementation level of $0.2 \%$ live weight. Under the post-grazing conditions, leaf biomass and the leaf/stem ratio traits were also least under the $0.2 \%$ supplemental feeding level. The structural and productive pasture traits, as well as the pasture morphogenetic indices exhibited effects of the grazing cycles. While dead material increased, tiller number and mass did not vary with the grazing cycles. The supplemental feeding of animals affected the marandu grass pasture traits. As the grazing season progressed from summer to autumn, pasture growth decreased and pasture structure was affected.
\end{abstract}

Index terms: Brachiaria brizantha, leaf area index, forage mass, morphogenesis, leaf stem ratio.

\section{Introdução}

A adequada caracterização do pasto é de grande auxílio para o entendimento das respostas das plantas forrageiras ao manejo do pastejo e, consequentemente, contribui na elaboração de estratégias mais adequadas para a exploração de seu potencial.Amensuração das características estruturais do pasto é de fundamental importância em ensaios de suplementação animal, para melhorar o entendimento da relação planta-animal (Roman et al., 2008).
O princípio da suplementação alimentar de animais criados no pasto é atender suas exigências nutricionais pela complementação do valor nutritivo da forragem, a fim de se alcançar o desempenho desejado (Euclides \& Medeiros, 2005). Contudo, interações pasto-suplementação podem ocorrer, e seu entendimento é importante para a exploração mais eficiente dessa prática de manejo. De acordo com Krysl \& Hess (1993), a suplementação pode promover a diminuição do tempo que os animais gastam 
pastejando e, consequentemente, pode reduzir o consumo de forragem. O consumo de energia oriunda do pasto pode ser reduzido (efeito substitutivo e combinado) ou inalterado (efeito aditivo), em resposta ao uso da suplementação alimentar dos animais, sendo este último o efeito desejável.

A suplementação alimentar dos animais afeta o consumo do pasto e pode influenciar suas caraterísticas produtivas e estruturais. Porém, poucos são os trabalhos que avaliam as influências de estratégias de suplementação alimentar sobre as características do pasto (Carvalho et al., 2007). A maioria dos trabalhos avalia apenas o efeito da suplementação alimentar sobre o desempenho animal ou sobre o ganho por área (Pilau et al., 2004; Coutinho-Filho et al., 2005; Roman et al., 2008).

$\mathrm{O}$ animal responde a variações na estrutura do pasto (Carvalho et al., 2007; Benvenutti et al., 2008) e à quantidade do suplemento que lhe é oferecido (Pardo et al., 2003). Em pastejo de lotação contínua de novilhos, Pardo et al. (2003) observaram, em pastagem nativa, queda no tempo de pastejo, na taxa de bocados e no número de bocados, em resposta ao aumento da suplementação alimentar dos animais com sorgo moído. O consumo de forragem de animais que recebem suplemento alimentar pode ser alterado, a depender da composição e da disponibilidade da forragem e do suplemento. Em geral, à medida que se aumenta a quantidade de suplemento oferecido, menor é a contribuição do pasto na alimentação do rebanho. Entretanto, Ruas et al. (2000) não observaram, em vacas Nelore, redução no consumo de pasto em razão do fornecimento diário de 1 ou $2 \mathrm{~kg}$ de concentrado.

A suplementação da dieta do animal criado no pasto pode afetar o comportamento ingestivo (Bremm et al., 2005) e a seletividade dos animais e, por consequencia, as características do pasto. Também a resposta dos animais à suplementação alimentar pode ser condicionada às características do pasto (Pilau et al., 2004; Roman et al., 2008). Na avaliação do desempenho de bezerras, em pasto de milheto (Pennisetum glaucum (L.) R. Br.), Roman et al. (2008) observaram que a suplementação energética permitiu que houvesse aumento na taxa de lotação no período inicial de pastejo, quando havia alta participação de lâminas foliares na massa de forragem. Também o ganho de peso aumentou à medida que a participação das lâminas na massa de forragem reduziu. Entretanto, não foi observada variação nas características estruturais e produtivas do pasto, em razão da suplementação alimentar dos animais. Pilau et al. (2004) também observaram aumento na taxa de lotação, em pastagem de aveia-preta e azevém, com o aumento da suplementação alimentar dos animais com farelo de trigo.

O objetivo deste trabalho foi avaliar as alterações estruturais e produtivas, em pasto de capim-marandu, manejado sob lotação rotacionada de novilhos de corte, em resposta à suplementação alimentar dos animais e aos ciclos de pastejo.

\section{Material e Métodos}

O experimento foi desenvolvido numa área de pastagem de capim-marandu (Brachiaria brizantha cv. Marandu), estabelecida em outubro de 2001, no setor de Forragicultura da Unesp, em Jaboticabal, SP, a $605 \mathrm{~m}$ de altitude, $21^{\circ} 15^{\prime} 22^{\prime \prime} \mathrm{S}$ e $48^{\circ} 18^{\prime} 58^{\prime \prime} \mathrm{W}$. O solo da área experimental foi classificado como Latossolo Vermelho (Santos et al., 2006). Foram avaliados os efeitos de três níveis de suplementação alimentar concentrada para novilhos de corte, sobre as características do pasto de capim-marandu, manejado em sistema de lotação rotacionada. A suplementação concentrada foi de $0,2,0,6$ e $1 \%$ do peso vivo do animal. $\mathrm{O}$ fornecimento do concentrado à base de polpa cítrica, milho, farelo de soja e ureia, com $18 \%$ de proteína bruta e $76 \%$ de nutrientes digestíveis totais (NDT), foi feito em baias individuais, em local adjacente aos piquetes experimentais. Diariamente, os animais eram recolhidos em suas respectivas baias às $9 \mathrm{~h}$ e permaneciam confinados até $14 \mathrm{~h}$, quando retornavam aos piquetes.

As avaliações referentes às características do pasto tiveram início em janeiro de 2003 e se estenderam até o mês de junho. Os dados climáticos foram coletados na Estação Agroclimatológica da Unesp, em Jaboticabal, SP. Os dados referentes às temperaturas máximas, mínimas e médias, bem como os dados de umidade relativa e precipitação, observados durante o período experimental, estão na Tabela 1.

Para avaliação das características da forragem e seus atributos morfofisiológicos e a mensuração dos possíveis efeitos dos três níveis de suplementação alimentar dos animais sobre as características do pasto, foram realizadas determinações em quatro ciclos de pastejo. 
Os ciclos de pastejo ocorreram nos seguintes períodos: ciclo 1, 10/1 a 19/2/2003; ciclo 2, 20/2 a 31/3/2003; ciclo $3,1 \% / 4$ a 11/5/2003 e ciclo $4,12 / 5$ a 21/6/2003.

A área experimental foi composta de 36 piquetes de $5.000 \mathrm{~m}^{2}$, dispostos em três blocos ao acaso. A avaliação do pasto em cada ciclo de pastejo foi feita em seis piquetes (dois de cada bloco). O valor de cada repetição foi considerado como a média dos dois piquetes avaliados. Em cada piquete, foram colocados 30 animais da raça Nelore, com peso médio inicial de $367 \mathrm{~kg}$. Foram escolhidos 10 animais para cada nível de suplementação.

Após um pastejo de uniformização, realizado em outubro e novembro de 2002, iniciaram-se as avaliações em 30/12/2002. O manejo adotado foi de cinco dias de ocupação e 35 dias de descanso.

O período de ocupação dos piquetes foi o mesmo para os diferentes níveis de suplementação. Assim, além das variações naturais da pastagem, observadas entre as faixas no piquete, a altura residual média dos piquetes variou em consequencia do nível de suplementação alimentar adotado, não tendo sido feito nenhum ajuste para compensar essa variação, a fim de se permitir a avaliação de possíveis diferenças entre os tratamentos.

Cada piquete, destinado às avaliações do pasto, foi dividido em três faixas para separar os animais com níveis diferentes de suplementação. Os níveis de suplementação foram sorteados em cada piquete e mantidos até o final das avaliações. A divisão foi feita por cerca elétrica de dois fios, com o uso de vergalhões de aço.

A adubação de pastagem foi feita com $150 \mathrm{~kg} \mathrm{ha}^{-1}$ por ano de $\mathrm{N}$ e $\mathrm{K}_{2} \mathrm{O}$ e $37,5 \mathrm{~kg} \mathrm{ha}^{-1}$ por ano de $\mathrm{P}_{2} \mathrm{O}_{5}$, distribuídos parceladamente após períodos de pastejo alternados, durante o período das águas.

Foram feitas as seguintes avaliações: massa de forragem pré-pastejo, massa de forragem pós-pastejo

Tabela 1. Médias mensais das temperaturas máximas (Tmáx), mínimas (Tmín) e médias (Tméd), da umidade relativa (UR) e da precipitação pluvial na área experimental.

\begin{tabular}{lccccc}
\hline Mês & Tmáx & $\begin{array}{c}\text { Tmín } \\
\text {---------------( }\left({ }^{\circ} \mathrm{C}\right)-------------\end{array}$ & $\begin{array}{c}\text { Tméd } \\
(\%)\end{array}$ & $\begin{array}{c}\text { Precipitação } \\
(\mathrm{mm})\end{array}$ \\
\hline Dez. 2002 & 32,0 & 20,3 & 25,0 & 77,1 & 242,2 \\
Jan. 2003 & 29,8 & 20,8 & 24,0 & 85,1 & 372,9 \\
Fev. 2003 & 32,4 & 20,4 & 25,4 & 75,5 & 153,5 \\
Mar. 2003 & 30,6 & 19,5 & 24,0 & 77,5 & 107,2 \\
Abr. 2003 & 29,8 & 17,5 & 22,6 & 74,8 & 124,1 \\
Maio 2003 & 26,8 & 13,3 & 19,0 & 70,7 & 86,7 \\
Jun. 2003 & 28,8 & 14,4 & 20,5 & 69,5 & 12,3 \\
\hline
\end{tabular}

(residual), altura do pasto em pré e pós-pastejo. Além dessas, foi realizado semanalmente, ao longo dos períodos de descanso, o levantamento dos seguintes atributos: índice de área foliar, interceptação da radiação incidente, massa de forragem disponível, altura do pasto e leitura do número e comprimento de folhas em perfilhos marcados.

Para as medições de altura do pasto, foram realizadas, em cada faixa, de 35 a 40 leituras ao acaso, com uma régua graduada em centímetros. Com o valor médio encontrado para a altura do dossel, localizavam-se as áreas da pastagem a serem cortadas para estimativa da massa de forragem. $\mathrm{O}$ corte foi feito rente ao solo, em duas áreas de $70 \times 70 \mathrm{~cm}$ por faixa (nível de suplementação). A forragem cortada foi, então, colocada em sacos de plástico e encaminhada ao laboratório de forragicultura para processamento. Procedeu-se à pesagem da forragem verde e, em seguida, retirou-se uma subamostra, de peso conhecido, para separação das frações: folha, colmo e material morto. Nessa subamostra, foi feita a contagem do número de perfilhos. Em seguida, esse material foi levado à estufa de ventilação forçada a $60^{\circ} \mathrm{C}$ por 72 horas, para posterior pesagem.

As avaliações do índice de área foliar (IAF) e interceptação luminosa (IL) foram feitas de forma não destrutiva, por meio do analisador de dossel Sunscan da Delta-T. Tais avaliações foram realizadas ao final do período de descanso (pré-pastejo) e após a saída dos animais dos piquetes (pós-pastejo), dentro de cada ciclo de pastejo. Foram tomadas 15 leituras em cada faixa, tendo-se obtido o valor médio para cada característica.

O acompanhamento das características morfogênicas do capim-marandu foi realizado semanalmente, ao longo do período de descanso, em três pontos por nível de suplementação, tendo-se marcado em cada ponto cinco perfilhos. Esses perfilhos foram trocados a cada ciclo de pastejo, dos quais foram registrados: o número de folhas e comprimento de folhas verdes e de folhas senescentes. Assim, foi possível determinar as taxas de alongamento e aparecimento foliar e a taxa de senescência. A taxa de alongamento do colmo foi calculada pela altura da lígula da última folha recémexpandida em relação ao solo, no início e no final de cada período de avaliação.

A análise estatística dos dados foi realizada segundo o modelo de parcelas subdivididas, tendo-se alocado 
os tratamentos (níveis de suplementação) nas parcelas e os ciclos de pastejo nas subparcelas. A comparação entre as médias dos tratamentos foi feita pelo teste de Tukey, com o programa SAEG (2000).

\section{Resultados e Discussão}

$\mathrm{Na}$ Tabela 2, estão apresentadas as características influenciadas pelos níveis de suplementação. Em geral, ao mais baixo nível de suplementação corresponderam os menores valores para as características apresentadas. Os dados indicam que houve maior uso da forragem pelos animais com o menor nível de suplementação alimentar. $\mathrm{O}$ efeito da suplementação alimentar dos animais sobre o pasto depende do nível ofertado e da composição do suplemento e do pasto, entre outros fatores (Moore, 1980; Euclides \& Medeiros, 2005). Esses aspectos, associados às variações inerentes ao processo de amostragem do pasto, podem ter limitado a detecção de diferenças entre os tratamentos com suplementação. Gomide et al. (2008) avaliaram o fornecimento de 3 e $6 \mathrm{~kg}$ de ração concentrada para vacas e observaram, em pasto de capim-tanzânia e capim-xaraés, efeito da suplementação somente na altura do dossel em pós-pastejo, em que a menor altura correlacionou-se ao menor nível de suplementação.

Pardo et al. (2003) constataram aumento no tempo de ruminação e ócio e redução no tempo de pastejo de novilhos, à medida que se elevou o nível de suplementação concentrada energética. Numa estratégia variável de fornecimento de suplementação concentrada para vacas de leite, Alvim et al. (1999) observaram que o consumo de matéria seca do pasto foi crescente, à medida que se reduziu o fornecimento de suplementação concentrada ao longo da lactação. Contudo, é importante lembrar que o comportamento do animal em pastejo responde também a características

Tabela 2. Índice de área foliar (IAF), interceptação luminosa (IL), relação folha/colmo (F/C) e massa de folhas secas (MS) do pasto de capim-marandu, em pré e pós-pastejo, em resposta aos níveis de suplementação alimentar dos $\operatorname{animais}^{(1)}$.

\begin{tabular}{lcccccc}
\hline Suplementação & \multicolumn{3}{c}{ Pré-pastejo } & & \multicolumn{2}{c}{ Pós-pastejo } \\
\cline { 2 - 4 } \cline { 7 - 7 } & IAF & IL $(\%)$ & F/C & & MS (kg ha $\left.{ }^{-1}\right)$ & F/C \\
\hline $0,2 \% \mathrm{PV}^{(2)}$ & $4,2 \mathrm{~b}$ & $89,1 \mathrm{~b}$ & $0,65 \mathrm{~b}$ & & $855 \mathrm{~b}$ & $0,33 \mathrm{~b}$ \\
$0,6 \% \mathrm{PV}$ & $4,8 \mathrm{a}$ & $91,4 \mathrm{a}$ & $0,72 \mathrm{a}$ & & $1.062 \mathrm{a}$ & $0,38 \mathrm{a}$ \\
$1,0 \% \mathrm{PV}$ & $4,6 \mathrm{a}$ & $91,8 \mathrm{a}$ & $0,72 \mathrm{a}$ & & $928 \mathrm{ab}$ & $0,35 \mathrm{ab}$ \\
\hline CV $(\%)$ & 6,8 & 1,3 & 11,0 & & 22,7 & 19,6 \\
\hline${ }^{(1)}$ Médias seguidas por letras iguais, nas colunas, não diferem entre si pelo \\
teste de Tukey, a 5\% de probabilidade. ${ }^{(2)}$ Peso vivo.
\end{tabular}

produtivas e estruturais da pastagem como altura, densidade, relação folha/colmo e percentual de material morto (Carvalho et al., 2007).

Como os valores de massa de forragem total, inicial e residual não foram influenciados pela suplementação, apenas pelos ciclos de pastejo (Tabela 3), os menores valores de massa de folhas residual e da relação folha/ colmo residual (Tabela 2), no menor fornecimento de suplemento, poderiam indicar maior consumo de forragem e até maior seletividade dos animais desse tratamento.

O pasto do tratamento com o menor nível de suplementação alimentar dos animais apresentou as relações $\mathrm{F} / \mathrm{C}$ mais baixas. Como as taxas de crescimento de folhas e de colmos não foram afetadas pela suplementação dos bovinos, mas apenas pelos ciclos de pastejo (Tabela 4), pode-se inferir que a redução na relação folha/colmo, sob menor nível de suplementação alimentar dos animais, se deva a uma maior seletividade dos animais nesta condição. Gomide et al. (2008) não detectaram alteração na relação F/C residual e no percentual de folhas residuais de capim-

Tabela 3. Massa de matéria seca (MS total), de material morto (MSMM) e de folhas (MS folha) do pasto de capimmarandu em pré-pastejo, e massa de folhas secas e relação folha/colmo (F/C) em pós-pastejo, conforme os ciclos de pastejo $^{(1)}$.

\begin{tabular}{|c|c|c|c|c|c|}
\hline \multirow[t]{2}{*}{ Ciclo } & \multicolumn{3}{|c|}{ Pré-pastejo } & \multicolumn{2}{|c|}{ Pós-pastejo } \\
\hline & MS total & MSMM & $\begin{array}{l}\text { MS folha } \\
\left.\mathrm{ha}^{-1}\right)\end{array}$ & MS folha & $\mathrm{F} / \mathrm{C}$ \\
\hline $1^{\underline{o}}$ & $6.740 \mathrm{ab}$ & $948 b$ & $2.225 \mathrm{a}$ & $1.047 \mathrm{a}$ & $0,31 \mathrm{ab}$ \\
\hline $2^{-}$ & $7.537 \mathrm{a}$ & $2.387 \mathrm{a}$ & $2.198 \mathrm{a}$ & $654 b$ & $0,26 b$ \\
\hline $3^{\circ}$ & $6.411 b c$ & $2.470 \mathrm{a}$ & $1.726 b$ & $1.073 \mathrm{a}$ & $0,41 \mathrm{a}$ \\
\hline $4^{\circ}$ & $5.647 \mathrm{c}$ & $2.672 \mathrm{a}$ & $1.195 \mathrm{c}$ & $1.018 \mathrm{ab}$ & $0,43 a$ \\
\hline $\mathrm{CV}(\%)$ & 9,0 & 11,9 & 8,8 & 22,7 & 11,0 \\
\hline
\end{tabular}

${ }^{(1)}$ Médias seguidas de letras iguais, nas colunas, não diferem entre si pelo teste de Tukey, a 5\% de probabilidade.

Tabela 4. Altura do pasto, índice de área foliar (IAF), interceptação luminosa (IL) e relação folha/colmo (F/C) do pasto de capim-marandu ao final do período de descanso de sucessivos ciclos de pastejo ${ }^{(1)}$.

\begin{tabular}{ccccl}
\hline Ciclo & Altura (cm) & IAF & IL $(\%)$ & F/C \\
\hline $1^{\circ}$ & $55,1 \mathrm{a}$ & $6,3 \mathrm{a}$ & $94,6 \mathrm{a}$ & $0,79 \mathrm{a}$ \\
$2^{\mathrm{o}}$ & $46,8 \mathrm{~b}$ & $4,7 \mathrm{~b}$ & $92,9 \mathrm{a}$ & $0,76 \mathrm{a}$ \\
$3^{\mathrm{o}}$ & $40,6 \mathrm{c}$ & $4,1 \mathrm{c}$ & $90,4 \mathrm{~b}$ & $0,66 \mathrm{ab}$ \\
$4^{\mathrm{o}}$ & $33,4 \mathrm{~d}$ & $3,1 \mathrm{~d}$ & $85,2 \mathrm{c}$ & $0,58 \mathrm{~b}$ \\
\hline CV (\%) & 4,3 & 6,8 & 1,3 & 11,0 \\
\hline
\end{tabular}

${ }^{(1)}$ Médias seguidas por letras iguais, nas colunas, não diferem entre si pelo teste Tukey, a $5 \%$ de probabilidade. 
tanzânia e capim-marandu, em resposta ao fornecimento diário de 3 ou $6 \mathrm{~kg}$ de suplemento concentrado para vacas de leite.

Observou-se forte associação entre os valores do índice de área foliar (IAF) e da interceptação luminosa (IL), cujos valores mais baixos foram observados na suplementação de $0,2 \%$ do peso vivo. O comportamento dessas duas características, principalmente do IAF, corrobora os dados encontrados para a relação $\mathrm{F} / \mathrm{C}$ e fortalece as pressuposições apontadas acima.

Notou-se redução dos valores de todas as características estruturais do pasto de capim-marandu com o suceder dos ciclos de pastejo (Tabela 4), o que mostra a diminuição do crescimento do pasto, à medida que se avançou para o outono. A altura média do dossel caiu de $55 \mathrm{~cm}$, no primeiro ciclo, para $33 \mathrm{~cm}$ ao final do período de descanso do quarto ciclo. Euclides et al. (2008) adotaram o pastejo alternado de 28 dias e observaram forte efeito da época de pastejo sobre a massa de forragem e os percentuais de folhas verdes, colmo e material morto do pasto, em três cultivares de Brachiaria brizantha.

A IL ficou acima dos $90 \%$, nos três primeiros ciclos de pastejo, mas não atingiu o valor de $95 \%$, considerado ideal para definir o início do pastejo (Silva \& Nascimento Júnior, 2007), o que pode ter limitado o acúmulo de forragem no pasto. O IAF caiu pela metade, entre o primeiro e o último ciclo de pastejo, o que mostra a drástica redução no crescimento vegetativo (folhas), sinalizado pelos baixos valores de aparecimento e alongamento foliares (Tabela 5).

A relação folha/colmo também caiu com o suceder dos ciclos de pastejo, como consequência da redução nos índices morfogênicos. No trabalho de Euclides et al. (2008), a relação folha/colmo do capim-marandu, em pré-pastejo, passou de 1,89, na época chuvosa, para 0,78 , na época seca. Esses valores são superiores ao encontrado no presente trabalho. É possível que tal diferença advenha, além de outros fatores, da menor massa de forragem observada por aqueles autores, bem como do menor período de descanso usado, de 28 dias. Apesar de ter havido redução também na taxa de alongamento do colmo com o suceder dos ciclos, os baixos valores desta característica, associados ao maior efeito sobre a taxa de alongamento foliar (Tabela 5), fizeram com que houvesse redução na relação folha/ colmo (Tabela 4). Isto mostra queda na qualidade da forragem disponível aos animais, o que aumenta a necessidade de suplementação para permitir maiores ganhos de peso. Roman et al. (2008) observaram, em milheto, que com o avanço do estádio fenológico da planta, houve maiores ganhos de peso dos animais em resposta à suplementação alimentar, em razão da redução na disponibilidade de folhas, bem como na relação $\mathrm{F} / \mathrm{C}$.

A biomassa de forragem total e de folhas também reduziu com o suceder dos ciclos de pastejo (Tabela 3 ). A partir do terceiro ciclo, a disponibilidade de folhas diminuiu e chegou ao quarto ciclo com valor ligeiramente superior a $1.000 \mathrm{~kg} \mathrm{ha}^{-1}$ de MS. Além disso, a presença de material morto se tornou elevada a partir do segundo ciclo e, embora não tenha diferido entre os demais ciclos, ela tendeu a crescer até o quarto ciclo. Assim, o desempenho animal tende a ser prejudicado pela menor disponibilidade de folhas e pela maior presença de material senescente na massa de forragem. Euclides et al. (1999) observaram que o consumo voluntário de matéria seca por novilhos, em pastagem de capim-colonião, capim-tanzânia e capim-tobiatã, apresentou correlações negativas com a percentagem de material morto e teor de FDN, e correlações positivas com a matéria seca verde total e de folhas, percentagem de folhas e relação matéria verde/ material morto. O prejuízo para a estrutura do pasto, com o avanço para a estação seca, é bem conhecido na literatura. A massa de folhas de capim-marandu, no período seco, foi de apenas $47 \%$ daquela observada na época chuvosa, e foi acompanhada de aumento no percentual de colmo e material morto (Euclides et al., 2008).

Tabela 5. Taxas de aparecimento (TApF), alongamento (TAF) e senescência (TSF) foliar, taxa de alongamento do colmo (TAC) e peso e número de perfilhos do capim-marandu em função dos sucessivos ciclos de pastejo $^{(1)}$.

\begin{tabular}{|c|c|c|c|c|c|c|}
\hline Ciclo & $\begin{array}{c}\text { TApF } \\
\text { (folha por perfilho por dia) }\end{array}$ & TAF & $\begin{array}{c}\text { TSF } \\
\text { perfilh }\end{array}$ & TAC & $\begin{array}{l}\text { Peso de perfilhos } \\
(\mathrm{g})\end{array}$ & $\begin{array}{l}\text { Perfilhos } \\
\left(\mathrm{n}^{\circ} \mathrm{m}^{-2}\right)\end{array}$ \\
\hline $1^{\underline{0}}$ & $0,103 \mathrm{a}$ & $15,6 b$ & $3,4 \mathrm{ab}$ & $3,91 \mathrm{a}$ & $1,21 \mathrm{a}$ & $570 \mathrm{bc}$ \\
\hline $2^{\underline{o}}$ & $0,112 \mathrm{a}$ & $19,7 \mathrm{a}$ & $3,8 \mathrm{a}$ & $0,98 \mathrm{~b}$ & $0,98 \mathrm{a}$ & $766 \mathrm{a}$ \\
\hline $3^{-}$ & $0,101 \mathrm{a}$ & $13,7 b$ & $3,1 \mathrm{ab}$ & $0,66 \mathrm{~b}$ & $1,00 \mathrm{a}$ & $650 \mathrm{~b}$ \\
\hline $4^{\circ}$ & $0,071 \mathrm{~b}$ & $9,7 \mathrm{c}$ & $1,5 \mathrm{~b}$ & $0,08 \mathrm{~b}$ & $1,11 \mathrm{a}$ & $522 \mathrm{c}$ \\
\hline $\mathrm{CV}(\%)$ & 6,6 & 12,6 & 41,3 & 87,1 & 11,5 & 7,4 \\
\hline
\end{tabular}

${ }^{(1)}$ Médias seguidas por letras iguais, nas colunas, não diferem entre si pelo teste Tukey, a 5\% de probabilidade. 
A acentuada elevação de material senescente, do primeiro para o segundo ciclo de pastejo, se deveu em parte ao acamamento da forragem ocorrido no primeiro pastejo, em razão da maior altura do dossel e, também, do próprio efeito do pastejo. O controle da estrutura do dossel, por meio da frequência e intensidade de pastejo, tem sido o foco de recentes trabalhos de manejo de pastagens (Gomide et al., 2007; Trindade et al., 2007). O objetivo é controlar o alongamento dos colmos, o aumento de material senescente e, assim, aumentar a eficiência de uso do pasto (Silva \& Nascimento Júnior, 2007).

Apesar do aumento da proporção de material morto no pasto, essa senescência não foi detectada nas avaliações morfogênicas (Tabela 5). Tal fato pode ser explicado pela metodologia adotada. A marcação de perfilhos foi feita considerando-se perfilhos vegetativos e, na maioria das vezes, perfilhos eretos. A amostragem para a estimativa da massa de forragem foi feita pelos cortes rentes ao solo, tendo-se coletado todo o material no interior da área de amostragem.

Tal explicação é válida também para a queda na massa residual de folhas, do primeiro para o segundo pastejo, ou seja, o material acamado após o pastejo foi coletado na primeira amostragem, para estimativa da massa de forragem. No segundo pastejo, esse material já estava senescente, o que elevou a massa de material senescente não mais considerado como folhas residuais.

A relação folha/colmo residual seguiu a mesma tendência da massa residual de folhas. $\mathrm{O}$ aumento nesta relação, nos últimos ciclos de pastejo, poderia sinalizar menor seletividade dos animais ou maior dificuldade de seleção, em resposta às alterações ocorridas na estrutura da vegetação com os ciclos de pastejo. Em pasto de capim-tanzânia sob lotação rotacionada, Gomide et al. (2008) também observaram maior relação folha/colmo residual no inverno, em relação ao verão. Segundo os autores, a estrutura do pasto no inverno pode ter limitado o pastejo seletivo e ocasionado a sobra de folhas.

Embora a suplementação alimentar dos animais represente uma estratégia de manejo, e este seja um dos fatores a influenciar as características morfogênicas (Chapman \& Lemaire, 1993), a suplementação avaliada não afetou os atributos morfogênicos do capim-marandu. As características morfogênicas avaliadas só mostraram o efeito de ciclos de pastejo
(Tabela 5). Esses dados seguem a mesma tendência dos valores apresentados na Tabela 2 e mostram o potencial de predição por meio dos índices morfogênicos, conforme demonstrado por Gomide et al. (2007) em capim-mombaça, e por Paciullo et al. (2008) em capim-braquiária.

Observou-se, com o suceder dos ciclos de pastejo, redução dos índices morfogênicos, o que sinaliza menor taxa de crescimento das plantas. Os maiores efeitos foram constatados sobre as taxas de alongamento e aparecimento foliar, no quarto ciclo de pastejo, quando as condições climáticas (chuva e temperatura) já não eram tão favoráveis ao desenvolvimento da gramínea (Tabela 1). Zeferino (2006) observou redução de 70\% na taxa de aparecimento foliar de B. brizantha no inverno, em relação ao verão e primavera.

A taxa de alongamento foliar (TAF) se mostrou mais alta durante o período de descanso do segundo ciclo de pastejo. Isto coincidiu com a redução na taxa de alongamento do colmo (TAC), em relação ao primeiro ciclo. Embora os valores da TAC sejam baixos, a associação desses resultados indica um maior investimento da planta no crescimento vegetativo, no segundo ciclo. Realmente, a incidência de perfilhos marcados que emitiram pendão floral foi baixa nesse período; isto, associado às condições climáticas adequadas para o desenvolvimento das plantas, explicaria o maior valor da TAF no segundo ciclo.

Os valores encontrados para a taxa de senescência foliar (TSF) foram, também, baixos. O menor valor observado no último ciclo de pastejo reflete o menor crescimento e menor fluxo de biomassa nesse período. Essa, assim como a TAC, foi uma característica bastante variável entre os perfilhos, em que alguns apresentaram folhas senescentes desde a sua marcação, e outros não apresentaram sinal de senescência durante a avaliação correspondente ao período de descanso de 35 dias. Alto coeficiente de variação foi observado, também, por Paciullo et al. (2008) para a TS de capim-braquiária.

$\mathrm{O}$ peso de perfilhos não variou com os ciclos de pastejo e apresentou valor médio de $1 \mathrm{~g}$. Era de se esperar que houvesse variação nessa característica, uma vez que se observou diferença nas taxas de aparecimento e alongamento foliares, componentes que contribuem para o desenvolvimento do perfilho (Skinner \& Nelson, 1995). O número de perfilhos aumentou do primeiro para o segundo ciclo de pastejo, possivelmente como resposta ao próprio efeito do 
pastejo em estimular o perfilhamento (Chapman \& Lemaire, 1993), o que coincidiu com boas condições de luz, temperatura e precipitação pluvial, nos meses de janeiro e fevereiro. Em seguida, houve redução no crescimento do pasto, em decorrência de condições climáticas menos favoráveis. Paciullo et al. (2008) observaram, em capim-braquiária, a redução de 581 para 310 perfilhos $\mathrm{m}^{-2}$ do verão para o inverno.

\section{Conclusões}

1. A suplementação alimentar de animais criados em pasto aumenta a relação folha/colmo da massa de forragem, tanto em pré como em pós-pastejo; aumenta também a massa de folhas pós-pastejo, a interceptação luminosa e o índice de área foliar.

2. Os ciclos de pastejo, do verão para o outono, afetam as características estruturais e produtivas do pasto, o que reduz a participação de folhas e a relação folha/colmo e aumenta a biomassa de material senescente.

\section{Agradecimentos}

À Fundação de Amparo a Pesquisa do Estado de São Paulo, pela concessão de bolsa e auxílio financeiro; à Faculdade de Ciências Agrárias e Veterinárias da Universidade Estadual Paulista, pela cessão de infraestrutura e apoio para realização do trabalho.

\section{Referências}

ALVIM, M.J.; VERNEQUE, R. da S.; VILELA, D.; CÓSER, A.C.; BOTREL, M. de A.; REZENDE, G.M. Estratégia de fornecimento de concentrado para vacas da raça Holandesa em pastagem de coast-cross. Pesquisa Agropecuária Brasileira, v.34, p.1711-1720, 1999.

BENVENUTTI, M.A.; GORDON, I.J.; POPPI, D.P. The effects of stem density of tropical swards and age of grazing cattle on their foraging behaviour. Grass and Forage Science, v.63, p.1-8, 2008.

BREMM, C.; ROCHA, M.G. da; RESTLE, J.; PILAU, A.; MONTAGNER, D.B.; FREITAS, F.K. de; MACARI, S.; ELEJALDE, D.A.G.; ROSO, D.; ROMAN, J.; GUTERRES, E.P.; COSTA, V.G. da; NEVES, F.P. Efeito de níveis de suplementação sobre o comportamento ingestivo de bezerras em pastagem de aveia (Avena strigosa Schreb.) e azevém (Lolium multiflorum Lam.). Revista Brasileira de Zootecnia, v.34, p.387-397, 2005.

CARVALHO, P.C.F.; TRINDADE, J.K.; MACARI, S.; FISHER, V.; POLI, C.H.E.C.; LANG, C.R. Consumo de forragens por bovinos em pastejo. In: SIMPÓSIO SOBRE MANEJO DA PASTAGEM, 24., 2007, Piracicaba. Produção de ruminantes em pastagens: anais. Piracicaba: Fealq, 2007. p.177-218.

CHAPMAN, D.F.; LEMAIRE, G. Morphogenetic and structural determinants of plant regrowth after defoliation. In:
INTERNATIONAL GRASSLAND CONGRESS, 17., 1993, Palmerston North. Proceedings. Palmerston North: New Zealand Grassland Association, 1993. p.95-104.

COUTINHO FILHO, J.L.V.; JUSTO, C.L.; PERES, R.M. Desenvolvimento ponderal de bezerras desmamadas em pastejo de Brachiaria decumbens com suplementação proteica e energética. Pesquisa Agropecuária Brasileira, v.40, p.817-823, 2005.

EUCLIDES, V.P.B.; MACEDO, M.C.M.; VALLE, C.B. do; BARBOSA, R.A.; GONÇALVES, W.V. Produção de forragem e características da estrutura do dossel de cultivares de Brachiaria brizantha sob pastejo. Pesquisa Agropecuária Brasileira, v.43, p.1805-1812, 2008

EUCLIDES, V.P.B.; MEDEIROS, S.R. de. Suplementação animal em pastagens e seu impacto na utilização da pastagem. In: SIMPÓSIO SOBRE MANEJO DA PASTAGEM, 22., 2005, Piracicaba. Teoria e prática da produção animal em pastagens: anais. Piracicaba: Fealq, 2005. p.33-70.

EUCLIDES, V.P.B.; THIAGO, L.R.L.S.; MACEDO, M.C.M.; OLIVEIRA, M.P. Consumo voluntário de forragem de três cultivares de Panicum maximum sob pastejo. Revista Brasileira de Zootecnia, v.28, p.1177-1185, 1999.

GOMIDE, C.A. de M.; COSTA, I.A.; VILELA, D.; LIMA, A.M.; PACIULlO, D.S.C.; CASTRO, C.R.T.; BRUSCHI, J.H. Características do capim-tanzânia e capim-xaraés sob pastejo de vacas com dois níveis de suplementação concentrada. In: CONGRESSO NORDESTINO DE PRODUÇÃO ANIMAL, 5., 2008, Aracaju. Anais. Aracaju: Sociedade Nordestina de Produção Animal, 2008. 1 CD-ROM.

GOMIDE, C.A. de M.; GOMIDE, J.A.; ALEXANDRINO, E. Características estruturais e produção de forragem em pastos de capim-mombaça submetidos a períodos de descanso. Pesquisa Agropecuária Brasileira, v.42, p.1487-1494, 2007.

KRYSL, L.J.; HESS, B.W. Influence of supplementation on behavior of grazing cattle. Journal of Animal Science, v.71, p.2546-2555, 1993.

MOORE, J.E. Forage crops. In: HOVELAND, C.S. (Ed.). Crop quality, storage and utilization. Madison: American Society of Agronomy, 1980. p.61-91.

PACIULLO, D.S.C.; CAMPOS, N.R.; GOMIDE, C.A.M.; CASTRO, C.R.T. de; TAVELA, R.C.; ROSSIELLO, R.O.P. Crescimento de capim-braquiária influenciado pelo grau de sombreamento e pela estação do ano. Pesquisa Agropecuária Brasileira, v.43, p.917-923, 2008.

PARDO, R.M.P.; FISCHER, V.; BALBINOTTI, M.; MORENO, C.B.; FERREIRA, E.X.; VINHAS, R.I.; MONKS, P.L. Comportamento ingestivo diurno de novilhos em pastejo submetidos a níveis crescentes de suplementação energética. Revista Brasileira de Zootecnia, v.32, p.1408-1418, 2003.

PILAU,A.; ROCHA, M.G. da; RESTLE, J.; ESTIVALET, R.; NEVES, F.P.; QUADROS, B.P. de. Recria de novilhas de corte com diferentes níveis de suplementação energética em pastagem de aveia-preta e azevém. Revista Brasileira de Zootecnia, v.33, p.2104-2113, 2004.

ROMAN, J.; ROCHA, M.G. da; GENRO, T.C.M.; SANTOS, D.T. dos; FREITAS, F.K. de; MONTAGNER, D.B. Características 
produtivas e estruturais do milheto e sua relação com o ganho de peso de bezerras sob suplementação alimentar. Revista Brasileira de Zootecnia, v.37, p.205-211, 2008.

RUAS, J.R.M.; TORRES, C.A.A.; VALADARES FILHO, S. de C.; PEREIRA, J.C.; BORGES, L.E.; MARCATTI NETO, A. Efeito da suplementação proteica a pasto sobre consumo de forragens, ganho de peso e condição corporal, em vacas Nelore. Revista Brasileira de Zootecnia, v.29, p.930-934, 2000.

SAEG. SAEG: sistema para análises estatísticas. Versão 8.0. Viçosa: UFV, 2000.

SANTOS, H.G. dos; JACOMINE, P.K.T.; ANJOS, L.H.C. dos; OLIVEIRA, V.A. de; OLIVEIRA, J.B. de; COELHO, M.R.; LUMBRERAS, J.F.; CUNHA, T.J.F. (Ed.). Sistema brasileiro de classificação de solos. 2.ed. Rio de Janeiro: Embrapa Solos, 2006. 306 .

SILVA, S.C. da; NASCIMENTO JÚNIOR, D. do. Avanços na pesquisa com plantas forrageiras tropicais em pastagens: características morfofisiológicas e manejo do pastejo. Revista Brasileira de Zootecnia, v.36, p.121-138, 2007.

SKINNER, R.H.; NELSON, C.J. Elongation of the grass leaf and its relationship to the phyllochron. Crop Science, v.35, p.4-10, 1995.

TRINDADE, J.K. da; SILVA, S.C. da; SOUZA JÚNIOR, S.J. de; GIACOMINI, A.A.; ZEFERINO, C.V.; GUARDA, V. del A.; CARVALHO, P.C. de F. Composição morfológica da forragem consumida por bovinos de corte durante o rebaixamento do capim-marandu submetido a estratégias de pastejo rotativo. Pesquisa Agropecuária Brasileira, v.42, p.883-890, 2007.

ZEFERINO, C.V. Morfogênese e dinâmica do acúmulo de forragem em pastos de capim-marandu (Brachiaria brizantha (Hochst. ex A. Rich) cv. Marandu) submetidos a regime de lotação intermitente por bovinos de corte. 2006. 193p. Dissertação (Mestrado) - Escola Superior de Agricultura Luiz de Queiroz, Piracicaba.

Recebido em 27 de outubro de 2008 e aprovado em 30 de abril de 2009 